\title{
THE S-BAND TRANSMITTER DESIGN FOR THE INSTITUTE OF ACCELERATING SYSTEMS AND APPLICATIONS RACETRACK MICROTRON
}

\author{
A. Hawkins, W. North, C. Wolcott, A. Zolfaghari, MIT-Bates; \\ D. P. Economou, D. Baltadoros, A. V. Filippas, A. Karabarbounis, \\ N. Papanicolas, E. Stiliaris, N.Uzunoglou, IASA-Greece;
}

\section{Abstract}

A high-power CW (continuous-wave) source, at 2380 $\mathrm{MHz}$, for the IASA (Institute of Accelerating Systems and Applications), (Athens, Greece), Microtron (see Table 1.) is based on the CPI (Communications and Power Industries) type VKS-8270 multi-cavity klystron. The high-level DC power conditioning for the klystron uses an existing high-voltage transformer-rectifier (HVPS) and variable-voltage transformer (VVT), designed to operate from $60 \mathrm{~Hz}$ power, whereas the local power is at $50 \mathrm{~Hz}$. Other features include a new electronic crowbar system and high-speed primary-power disconnect.

\section{INTRODUCTION}

To transplant the Microtron RF source to its new venue, making use of its iron-cored components, adjustments are made for the use of $50 \mathrm{~Hz}$ primary power instead of $60 \mathrm{~Hz}$. In addition, a more effective electronic crowbar and surge-current limiting, for protection in the event of a klystron gun arc, is provided. A simplified schematic of the system is shown in Figure 1.

Table 1: The main characteristics of the IASA Cascade RaceTrack Microtron.

\begin{tabular}{|l|c|c|c|}
\cline { 2 - 4 } \multicolumn{1}{c|}{} & Injector & RTM I & RTM II \\
\hline Injection Energy [MeV] & & 6.5 & 41 \\
\hline Gain per Turn [MeV] & & 1.32 & 8 \\
\hline Number of Recirculations & & 26 & 25 \\
\hline Max Output Energy [MeV] & 6.5 & 41 & 240 \\
\hline Max Current [uA] & 600 & 100 & 100 \\
\hline Incremental Number v & & 1 & 1 \\
\hline Magnets Field [Tesla] & & 0.22 & 1.34 \\
\hline Spacing [m] & 8.8 & 3.25 & 8.7 \\
\hline RF Power Consump. [kW] & 117 & 29 & 168 \\
\hline
\end{tabular}

\section{Effect of $50 \mathrm{~Hz}$ Line Frequency}

The VVT and the HVPS were designed to operate from $13.8 \mathrm{kV}, 3$-phase, $60 \mathrm{~Hz}$ power. With $50 \mathrm{~Hz}$ power the voltage must be reduced by a factor of 50/60 for the volt-time integrals to be the same to avoid iron-core saturation. The maximum line voltage is thus $11.5 \mathrm{kV}$. The local power is at $20 \mathrm{kV} \mathrm{L-L}$, which must be stepped down to $11.5 \mathrm{kV}$. This is done with a "bucking" transformer, T1, whose primaries are across the $20 \mathrm{kV}$ and whose $8.5 \mathrm{kV}$ secondaries are in series-opposition with the $20 \mathrm{kV}$ line, yielding $11.5 \mathrm{kV}$ L-L with only $74 \%$ of the $\mathrm{kVA}$ rating of a $20 \mathrm{kV} / 11.5 \mathrm{kV}$ transformer.

\section{AC to DC Converter}

\subsection{Variable-Voltage Transformer (VVT)}

The VVT is of dry construction, air cooled, and housed in an enclosure $8.8^{\prime}$ x 7.5' x 9.1', weighing 15,000 pounds. At its simplest, the VVT, T2, is a linear-format version of a variable autotransformer. The advantage of linear is increased contact surface area. The disadvantage is increased leakage inductance of the magnetic circuit. The VVT circumvents leakage inductance by means of a transformer with a multiple-tapped secondary winding. The multiple taps are connected to points along the linear winding, short-circuiting the leakage reactance. The E70381 VVT is far more complicated than just three ganged variable transformers however. Each phase has two linear commutating windings and a transformer whose primary winding bridges the incoming line and which has dual secondary windings, each with 14 taps. There are two sets of dual brushes on each commutating winding, one at each end, motor driven in opposite directions. The brushes are connected to the primary of each phase of a "buck-boost" output transformer. One side of each secondary winding is connected to a tap on the input transformer secondary, which establishes the mid-point of the adjustment range. With the brushes opposite each other, the primary voltage is zero and the output is the midpoint voltage. As the brushes are driven away from each other in one direction, the primary voltage increases in the "buck" direction reducing the output. When driven in the opposite direction, the primary voltage increases in the "boost" direction increasing the output. With $13.8 \mathrm{kV}, 60 \mathrm{~Hz}$ input, the minimum voltage is $6.2 \mathrm{kV}$, and the maximum, no-load, is $14.1 \mathrm{kV}, 28 \%$ buck and boost. With the $11.5 \mathrm{kV}, 50 \mathrm{~Hz}$ input the corresponding values are 5.2 and $11.75 \mathrm{kV}$.

\subsection{High-Voltage AC-DC Converter (HVPS)}

The E-18645 HVPS is oil-insulated, self-cooled, housed in a steel tank $5.25^{\prime} \times 7.1^{\prime} \times 8.8^{\prime}$, and weighs 28,600 pounds. 
The HVPS, PS1, has a step-up transformer with a single 3-phase delta primary and two secondary windings, one delta and the other wye, having identical line-line voltages. A three-phase, full-wave rectifier (six-pulse) is connected to each set of windings, and the rectifier outputs are connected in series-aiding. There is an inherent 30-degree phase difference between the outputs of the delta and wye windings, which interleaves the conduction intervals of the 6-pulse rectifiers, producing a 12-pulse output with 30-degree conduction intervals. The first theoretical ripple component is the $12^{\text {th }}$ harmonic, or $600 \mathrm{~Hz}$, having a no-load amplitude of 2/143 of the DC component. The average output is 0.9886 times the peak $\mathrm{AC}$ input and the peak-valley ratio is 0.97 . Line voltage amplitude imbalance, however, produces ripple components at 2, 4 and 6 times the line frequency. Load current produces phase-phase commutation delays in the rectification process because of $\mathrm{AC}$ source inductive reactance, primarily leakage reactance. Because of these imperfections an internal ripple filter comprising a $7.5 \mathrm{H}$ voltage across which is proportional to klystron beam current.

\section{Protection for the Klystron}

The klystron, V1, is prone to breakdown between cathode and body, which short-circuits the DC input. The threats to the klystron are the energy and charge stored in the capacitance and the charge transport produced by shortcircuit current before the switchgear disconnects the input line.

\subsection{Capacitive Stored Energy and Charge}

The energy and charge stored in the $4.3 \mathrm{uF}$ capacitor at 54 $\mathrm{kV}$ are $6.3 \mathrm{~kJ}$ and 0.23 Coulomb. The fundamental protection against stored energy is current-limiting resistance in series with the klystron cathode. It is optimally effective if it limits current to 1000 A or less.

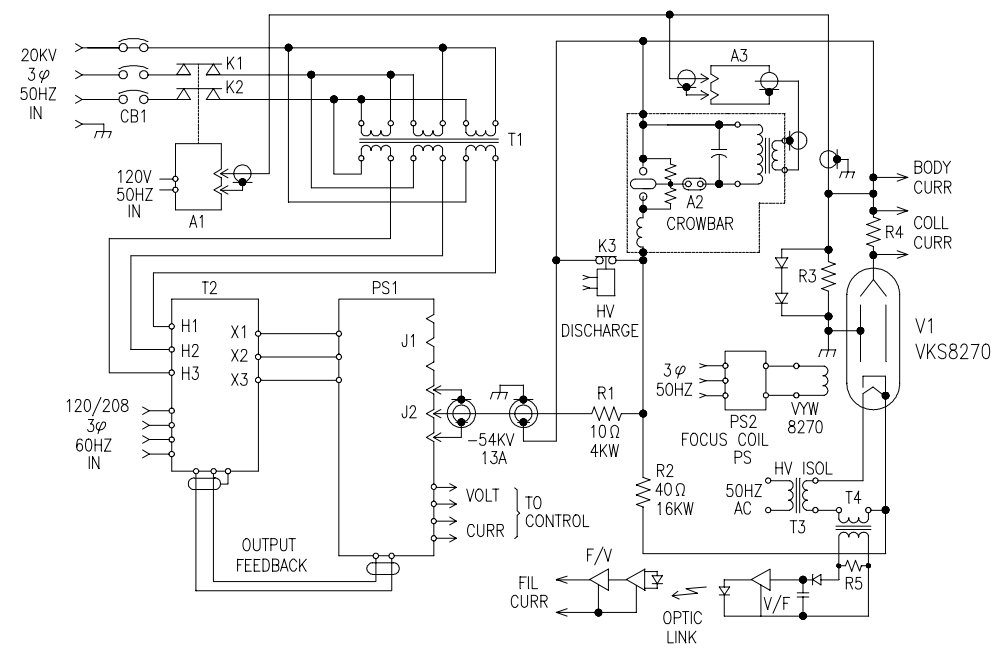

Figure 1: A simplified schematic of the IASA transmitter

series inductor and a shunt capacitor of $3 \mathrm{uF}$ is used. With $13.8 \mathrm{kV}, 60 \mathrm{~Hz}$, the combination of VVT and HVPS produces an output variable from $-33 \mathrm{kVDC}$ to -65 $\mathrm{kVDC}$, at $16.5 \mathrm{ADC}$. With $11.5 \mathrm{kV}, 50 \mathrm{~Hz}$ input, the output range is $-27.5 \mathrm{kVDC}$ to $-54 \mathrm{kVDC}$. In order for the filter to have the same ripple-reduction at $50 \mathrm{~Hz}$ as at $60 \mathrm{~Hz}$ the shunt capacitance is increased by the square of $60 / 50$, or 1.44 , to $4.3 \mathrm{uF}$.

An internal 65 Megohm resistor is connected to the HV terminal of the transformer-rectifier. At the low end of the resistor is a current meter and an $8.2 \mathrm{kOhm}$ fixed and 5 $\mathrm{kOhm}$ variable resistance, in series with the low-voltage return. The voltage across the resistors is fed to the control input of the VVT, for voltage regulation. The current meter output is proportional to output voltage. In series with the low-voltage return to the rectifier is a highspeed current-overload relay and a $20 \mathrm{~A}$. meter shunt, the
At this current vacuum arcs are stable and have voltage drop of 20 Volts or less. This calls for approximately 50 Ohms series resistance. Following an arc, all but $20 \mathrm{~V}$ of the capacitor voltage will be across the series resistor. Most of the $6.3 \mathrm{~kJ}$ is dissipated in the resistor. With the VKS-8270 operated at $54 \mathrm{kV}$ beam voltage, and corresponding beam current of 11.4 A the resistor voltage drop is $570 \mathrm{~V}$, reducing actual klystron beam voltage to $53.4 \mathrm{kV}$.

\subsection{Short-Circuit Power Supply Current}

The second component of charge transport is short-circuit power supply current, limited by the series reactance on the AC side of the rectifier, measured to be a total of $10 \%$. The rated output current is $16.5 \mathrm{~A}$. The short-circuit current will be $165 \mathrm{~A}$. Opening within $1 / 2$ cycle, 10 
milliseconds at $50 \mathrm{~Hz}$, the charge transport, with halfsinusoidal waveform, is 1 Coulomb.

\subsection{Klystron Arc Energy and Discharge "Action"}

With no protection other than series resistance and $1 / 2-$ cycle primary interrupt, the energy dissipated in an arc, assuming constant arc drop of $20 \mathrm{~V}$, is $20 \mathrm{~V}$ x charge transport $=20 \mathrm{~V} \times 1.23 \mathrm{C}=24.6 \mathrm{~J}$. Also of importance is the "action" or the time integral of the square of the discharge current, which determines the temperature-rise of a conductor passing the current. The component due to stored energy is $6.3 \mathrm{~kJ} / 50 \mathrm{Ohms}=126$ Amp-squaredseconds. The component due to $1 / 2$-cycle follow current of 165 A peak is 136 Amp-squared-seconds. The total of 262 Amp-squared-seconds is slightly more than the 207 required to fuse an AWG \#30 copper wire. This is often the criterion of efficacy of a protection system.

\subsection{Series Resistor Characteristics}

The resistor must hold off at least $54 \mathrm{kV}$, dissipating an average power of $6.5 \mathrm{~kW}$, during normal operation, and a total impulse energy of $6.3 \mathrm{~kJ}$, due to stored energy and $6.8 \mathrm{~kJ}$ due to short-circuit power-supply current without exceeding a peak temperature of $375{ }^{\circ} \mathrm{C}$. Resistors of the edge-wound type are custom-designed by Milwaukee Resistor Corp to have sufficient surface area and resistive mass to do this, using special high-mass/Ohm resistive alloys. A total of ten 5-Ohm, 2-kW resistors are used.

\subsection{Electronic Crowbar}

It is considered prudent to additionally protect the klystron by means of an electronically-triggered low impedance, such as another arc, shunting the high-voltage isolated by a portion of the series resistance. In this case a mid-plane-triggered air-insulated spark gap, of the "infinite-voltage-range" type, A2 is used. It is triggered by the output of the crowbar driver, A3, which is steppedup to a $200 \mathrm{kV}$ open-circuit pulse by a pulse transformer and applied to the midplane electrode through a sharpening spark gap. The spacings between the midplane electrode and the upper and lower main electrodes are biased so that the trigger arc will be to the electrode having the inductor in series with it, which prevents the arc from short-circuiting the trigger source, allowing the gap between midplane and the other electrode to ionize as well, without the need for external high voltage between main electrodes, hence "infinite voltage range". The 50 $\mathrm{Ohm}$ series resistor is divided into two segments, one of $10 \mathrm{Ohms}, \mathrm{R} 1$, and one of $40 \mathrm{Ohms}$, R2. The high-side of the crowbar is connected to their intersection. The 40 Ohms in series with the klystron is much higher in impedance than the fired crowbar, assuring that most of charge is diverted from the klystron. The maximum peak current through the crowbar is $54 \mathrm{kV} / 10 \mathrm{Ohms}=5400 \mathrm{~A}$.. Having a crowbar means that the $10-\mathrm{Ohm}$ segment in series with the crowbar must meet all of the impulse criteria described in 4.4 , since the crowbar protects the remaining $40 \mathrm{Ohms}$ as well as the klystron.

\subsection{High-Speed Mains Disconnect}

The $20 \mathrm{kV}$ circuit breaker, shown as CB1, has an opening time of 3-5 line cycles, which is too long. At $20 \mathrm{kV}$ line voltage, solid-state SCR-based relays are impractical. Vacuum relays, however, with close-spaced contacts, can achieve opening times as short as 2 milliseconds, or $1 / 5$ cycle, giving 1/2-cycle clearing time, assuming the postopening arc extinguishes at the current zero crossing. Only two such relays, Ross Engineering HBF-51-NC, K1 and $\mathrm{K} 2$, are required, with normally-closed contacts. They are driven open by the output of an SCR-switched stored-energy driver, type HCB, A1.

\section{Klystron RF Amplifier}

The VKS-8270 multi-cavity CW klystron amplifier has coaxial RF input, waveguide RF output, electromagnet beam focussing, and liquid cooling. Filament power is from a high-voltage isolation transformer, T3. Filament current is monitored by series transformer, $\mathrm{T} 4$, developing voltage across $\mathrm{R} 5$, which is rectified, converted to a train of optic pulses with frequency proportional to voltage, and converted back to voltage, at ground level. Focus coil excitation is from PS2. Voltages proportional to body and collector current are developed across R3 and R4. R3 is shunted by high-surge-current diodes to conduct the current resulting from a gun arc. The voltage drop is clamped to $7 \mathrm{~V}$, which is the fault input to the crowbar driver and the stored-energy driver, which have $5 \mathrm{~V}$ input thresholds.

Klystron tests, at $2380 \mathrm{MHz}$, with beam voltage of 65 $\mathrm{kVDC}$ and current of 15.1 A showed power output of 490 $\mathrm{kW}$ with 1 Watt RF input. With $50 \mathrm{~Hz}$ primary power, however, the DC beam voltage available is only $54 \mathrm{kV}$. Beam current drops as the $3 / 2$ power of voltage and beam power by the $5 / 2$ power. RF output drops even faster than the cube of beam voltage because it is proportional to the square of the fundamental-frequency RF current traversing the output gap, which, at best, diminishes as the cube of beam voltage. As beam voltage is reduced, the spacing between RF cavities is no longer optimum because the beam velocity is lower and bunching effectiveness is diminished, reducing further the RF component of current. The peak RF voltage across the output gap falls more rapidly than beam voltage. Some of the loss in RF power can be regained by means of a properly positioned iris in the output waveguide to effect an increase in the RF impedance reflected into the RF output gap of the klystron, restoring the match between $\mathrm{RF}$ impedance and electron-beam impedance, which varies as the $1 / 2$ power of beam voltage. 